MATEC Web of Conferences 22,05005 (2015)

DOI: $10.1051 /$ matecconf/ 20152205005

(C) Owned by the authors, published by EDP Sciences, 2015

\title{
Influence Analysis of Shell Material and Charge on Shrapnel Lethal Power
}

\author{
Lin Wang, Xiujuan Gao, Xiaohui Li \& You Zhao \\ Baicheng Ordnance Test Center of China, Jilin University, Baicheng, Jilin, China
}

\begin{abstract}
To compare the shrapnel lethal power with different shell material and charge, LS-DYNA was used to numerically simulate four kinds of shrapnel lethal power. The shell material was 58SiMn, 50SiMnVB or $40 \mathrm{Cr}$, whereas the charge was RL-F. And the shell material was $58 \mathrm{SiMn}$, whereas the charge was TNT. The shell rupture process and lethal power test were analyzed. The results show that, the lethal power of RL-F charge increase by $25 \%, 45 \%, 14 \%$ compared with the TNT charge, whereas the shell material was $58 \mathrm{SiMn}, 50 \mathrm{SiMnVB}$, $40 \mathrm{Cr}$. And then the guarantee range and lethal power can be improved by using the high explosive and changing shell material, whereas the projectile shape coefficient is invariable.
\end{abstract}

Keywords: numerical simulation; high explosives; shell material; shrapnel; lethal power

\section{INTRODUCTION}

Aluminized explosive has been widely used in various kinds of ammunition, because it has higher explosion heat and explosive temperature and longer detonation reaction time. But in our country, TNT and RDX charge are still used in the large caliber shrapnel, such as $122 \mathrm{~mm}, 152 \mathrm{~mm}$ and $155 \mathrm{~mm}$ shrapnel. And then warhead lethal power is seriously affected, because the density, detonation velocity and detonation pressure of TNT are lower. The range and the lethal power of large caliber shrapnel can be improved by using the high explosive and selecting suitable shell material.

\section{THE INFLUENCING FACTORS OF SHRAPNEL}

Papers by Zhao Handong, Analysis on the Influencing Factors of the Lethality about Premade Fragments, Ma Yongzhong, Calculation on Casualty Area of $\mathrm{HE}$ and Analysis on Influential Factors, and Wang Lin, The Study on the Effect of Typical Fragment Mass on Projectile Power and the Control Methods, have studied the influencing of the fragment initial velocity, the fragment quality and quantity distribution, the fragment spatial distribution, the falling angle and the falling velocity on the lethal power ${ }^{[1-3]}$. These papers are not written from the analysis of shell material and explosives characteristics.

Detonation driving process and fragments dispersion trend of the large caliber shrapnel, which had different shell material and charge, were simulated with LS-DYNA in this paper. And the simulation results were compared with the ball cartridge experiment, to provide the reference for the designing of lethal power and high explosive warhead in large caliber shrapnel.

\section{THE SIMULATION MODE AND MATERIAL PARAMETERS}

\subsection{The finite element model}

The finite element model is shown in Figure 1. The shell material, quality and charge are shown in Table 1. To simplify the calculations and analysis, which was the effect tendency of material and charge to shrapnel lethal power, 1/4 model was used, and the material density, elastic modulus, Poisson ratio parameters of the model were modified. The initiation point was arranged in the warhead. Euler hexahedral network was used in charge and air, and the single point integral Lagrange hexahedral network was used in shell. Fluid-solid coupling was used to solve the interaction of the model. And then related constraints about boundary were set.

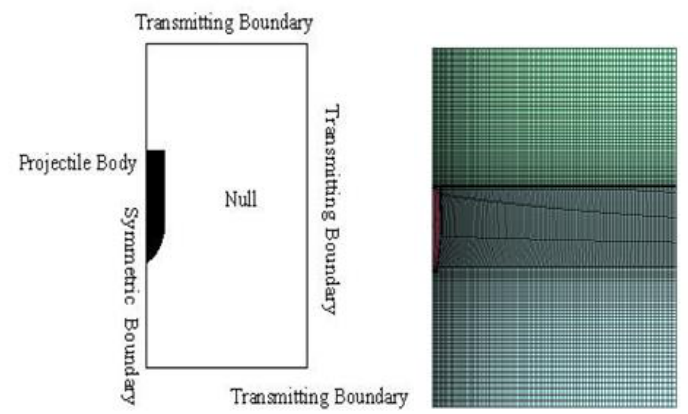

Figure 1. Numerical model and meshes

\subsection{The material mode and parameters}

High Explosive Burn material model and JWL state equation were used to describe TNT and RL-F. 
MATEC Web of Conferences

Table. 1: Parameters of the large calibre shrapnel

\begin{tabular}{lllllll}
\hline $\begin{array}{l}\text { Shell mate- } \\
\text { rial }\end{array}$ & $\begin{array}{l}\text { Shell quality } \\
(\mathrm{kg})\end{array}$ & Charge & $\begin{array}{l}\text { Charge quality } \\
(\mathrm{kg})\end{array}$ & $\begin{array}{l}\text { Material density } \rho \\
\left(\mathrm{kg} / \mathrm{m}^{3}\right)\end{array}$ & $\begin{array}{l}\text { Elastic modulus e } \\
(\mathrm{pa})\end{array}$ & $\begin{array}{l}\text { Poisson ratio } \\
\mu\end{array}$ \\
\hline $58 \operatorname{simn}$ & 18.07 & RL-F & 3.8 & 7850 & $2.07 \mathrm{E}+11$ & 0.270 \\
$50 \operatorname{simnvb}$ & 18.07 & RL-F & 3.8 & 7830 & $2.10 \mathrm{E}+11$ & 0.220 \\
$40 \mathrm{Cr}$ & 18.07 & RL-F & 3.8 & 7870 & $2.11 \mathrm{E}+11$ & 0.277 \\
$58 \operatorname{simn}$ & 18.27 & TNT & 3.2 & 7850 & $2.07 \mathrm{E}+11$ & 0.270 \\
\hline
\end{tabular}

Table. 2 Parameters of the TNT and RL-F

\begin{tabular}{ccccccccc}
\hline parameters & $\rho /\left(\mathrm{kg} \cdot \mathrm{m}^{-3}\right)$ & $\mathrm{D} /\left(\mathrm{m}^{-1} \mathrm{~s}^{-1}\right)$ & $\mathrm{A} /(\mathrm{GPa})$ & $\mathrm{B} /(\mathrm{GPa})$ & $\mathrm{R}_{1}$ & $\mathrm{R}_{2}$ & $\omega$ \\
\hline TNT & 1580 & 6856 & 214.714 & 10.337 & 3.96 & 1.403 & 0.50 \\
RL-F & 1720 & 7680 & 372.100 & 7.120 & 4.40 & 1.300 & 0.33 \\
\hline
\end{tabular}

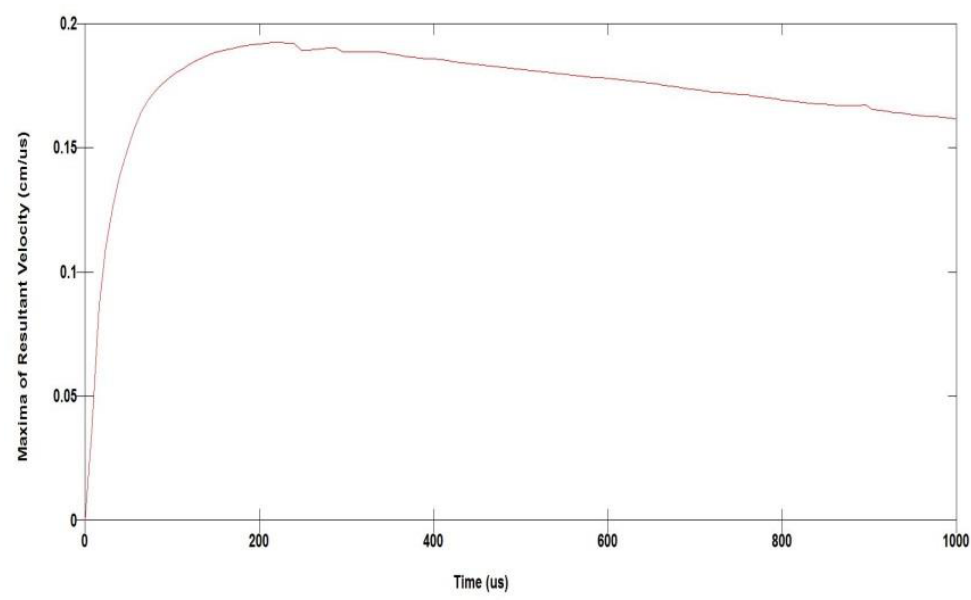

(a) $58 \mathrm{SiMn}$ shell TNT charge

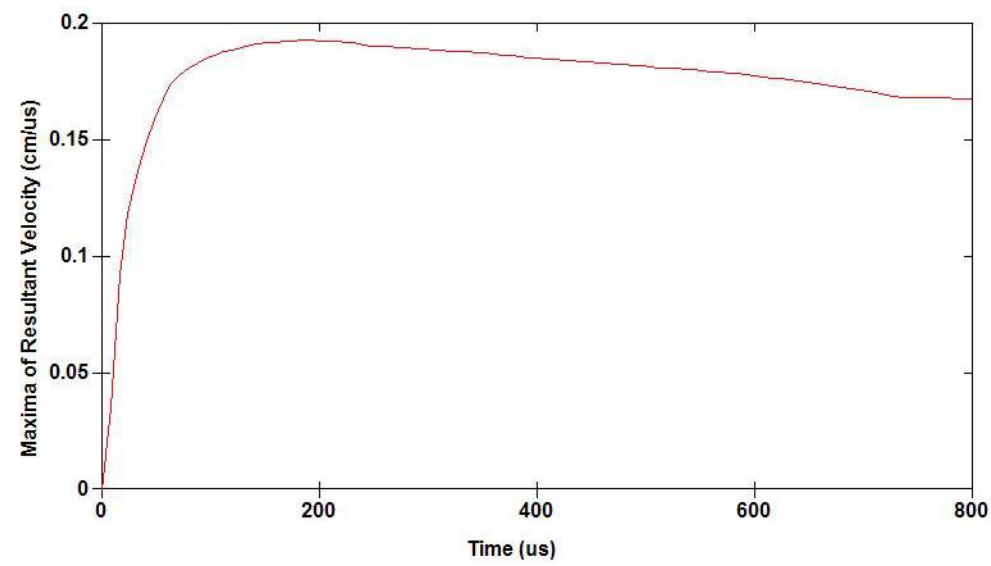

(b) $58 \mathrm{SiMn}$ shell RL-F charge 
ICETA 2015

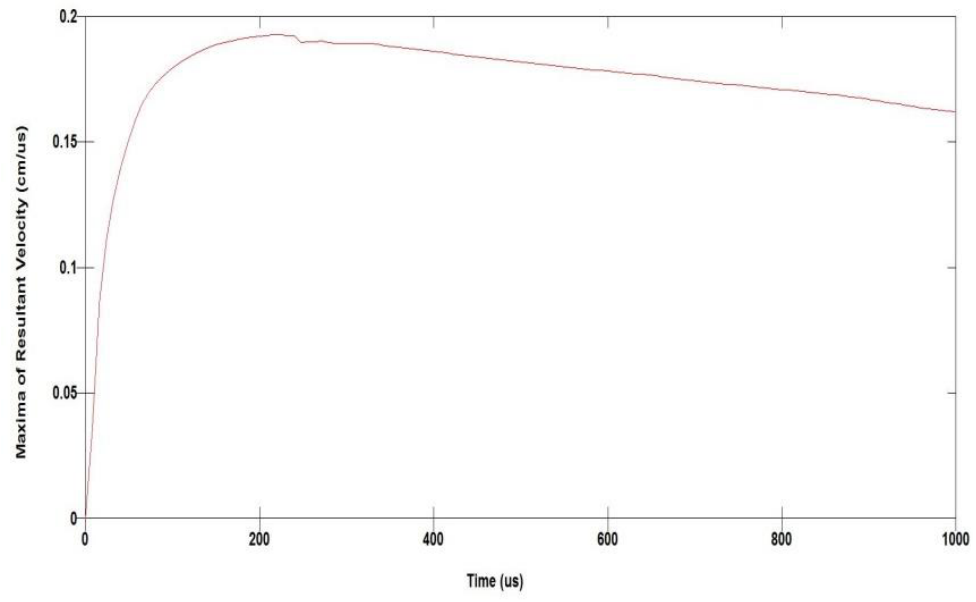

(c) $50 \mathrm{SiMnVB}$ shell RL-F charge

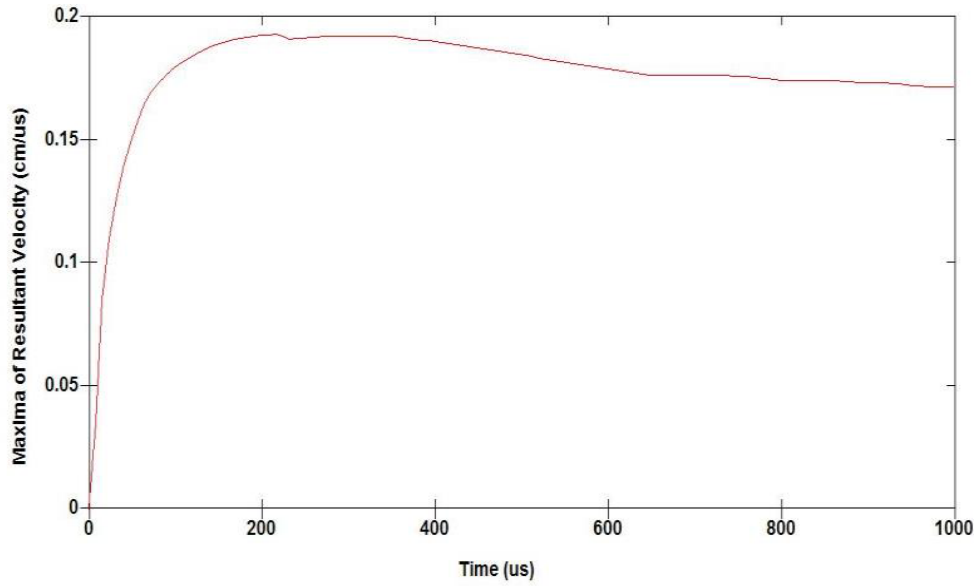

(d) $40 \mathrm{Cr}$ shell RL-F charge

Figure 2 .The curve of the maximum fragment flying velocity

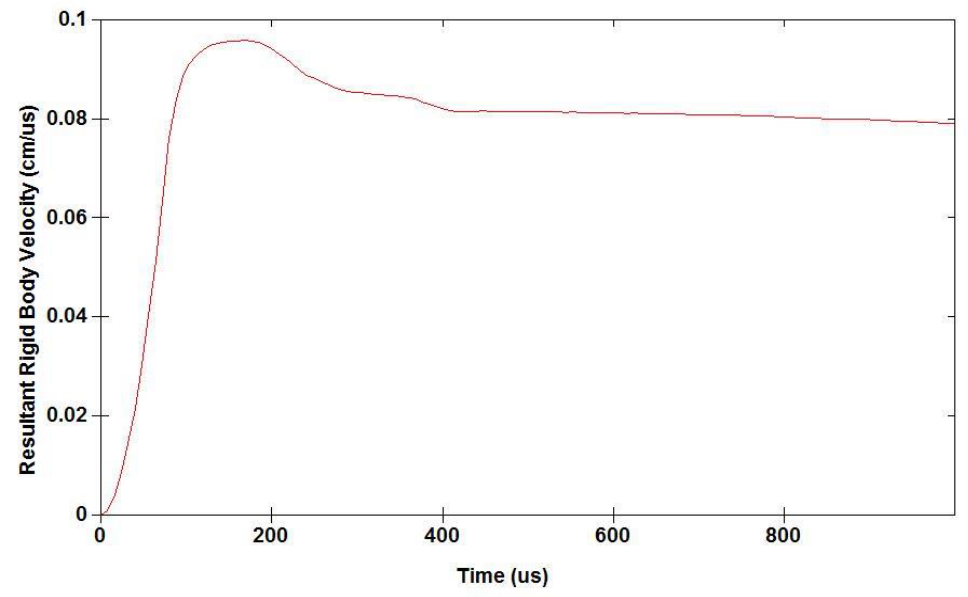

(a) 58SiMn shell TNT charge 
MATEC Web of Conferences

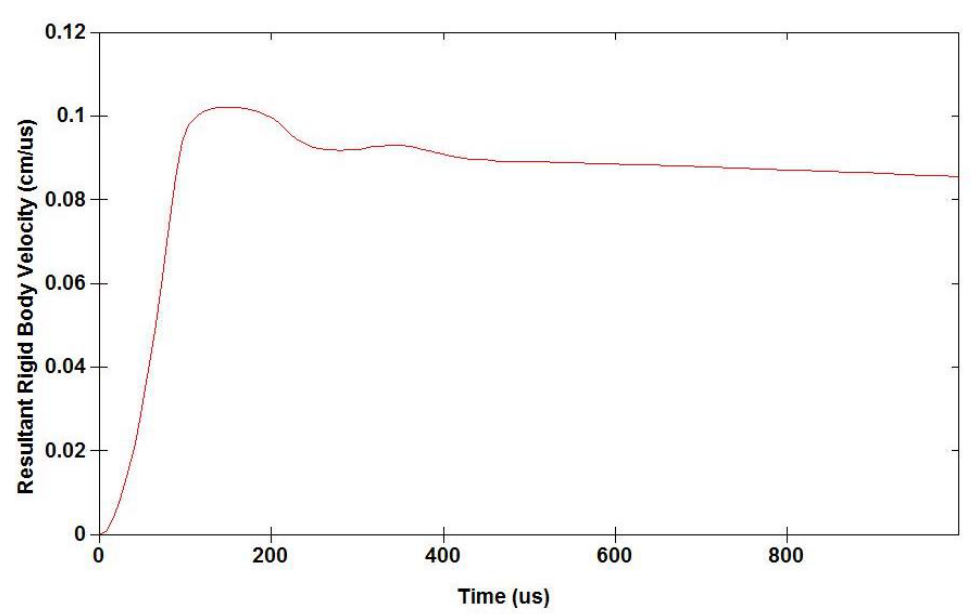

(b) $58 \mathrm{SiMn}$ shell RL-F charge

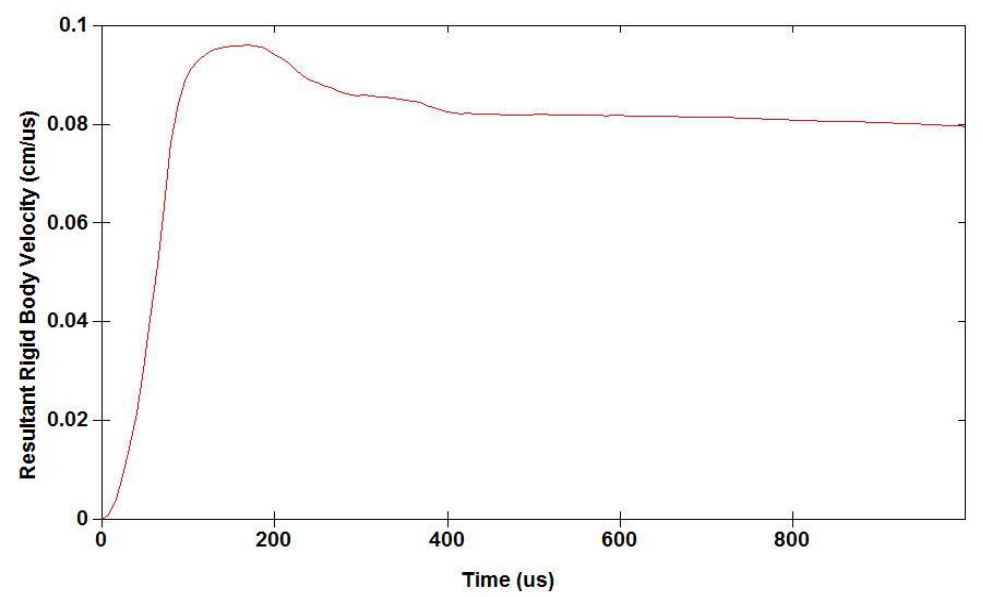

(c) $50 \mathrm{SiMnVB}$ shell RL-F charge

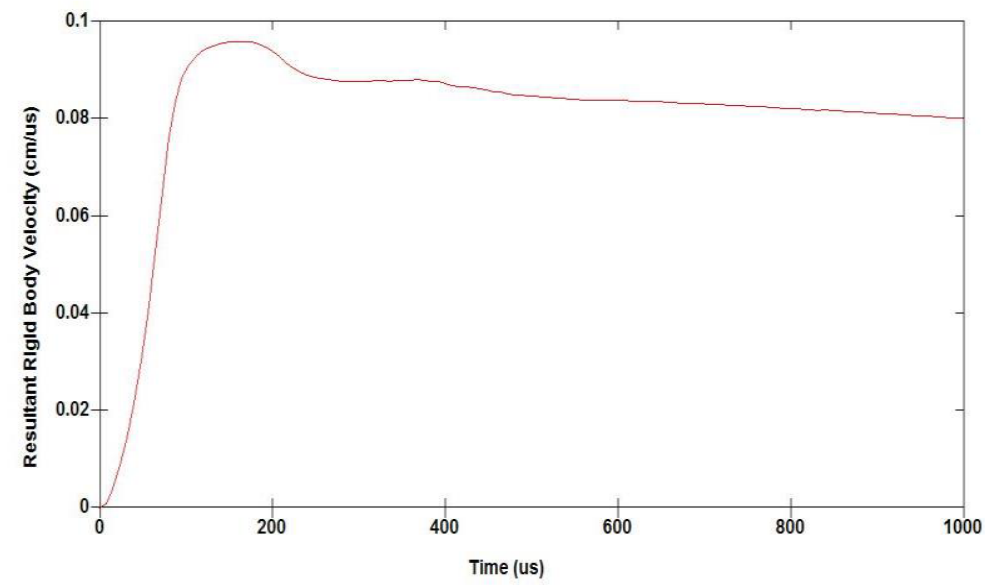

(d) $40 \mathrm{Cr}$ shell RL-F charge

Figure 3 .The curve of the average fragment flying velocity 
Johnson Cook material model and Gruneisen state the equation were used to describe shrapnel shell material which was $58 \mathrm{SiMn}, 50 \mathrm{SiMnVB}$ or $40 \mathrm{Cr}$. Explosive state equation about the pressure and volume is shown in Formula (1), and parameters are shown in Table $2^{[4-7]}$.

$$
P=A\left(1-\frac{\omega}{R_{1} V}\right) \mathrm{e}^{-R_{1} V}+B\left(1-\frac{\omega}{R_{2} V}\right) \mathrm{e}^{-R_{2} V}+\frac{\omega E}{V}
$$

Where $V=$ relative volume; $E=$ initial internal energy; $A, B, R_{1}, R_{2}, \omega=$ Constant.

\section{THE SIMULATION RESULTS ANALYSIS}

\subsection{The fragment velocity}

Four kinds of warhead were studied by numerical simulation with the model and the parameters. Figure 2 is the curve of the max fragment flying velocity, and Figure 3 is the curve of the average fragment flying velocity.

Analyzing on the results of Figure 2 and Figure 3, the fragment maximum velocity and average velocity are the most, whereas shell material is $58 \mathrm{SiMn}$ and charge is RL-F. When shell material is $50 \mathrm{SiMnVB}$ and charge is RL-F, the velocity result takes second place. When shell material is $40 \mathrm{Cr}$ and charge is RL-F, the velocity result takes third place. When shell material is $58 \mathrm{SiMn}$ and charge is TNT, the velocity result takes fourth place. When material circumstances are the same, RL-F explosive is more powerful than the TNT explosive power, and it results in increasing the initial velocity. When loading condition is the same, shell material of $40 \mathrm{Cr}$ would lead to smaller muzzle velocity than other materials.

\subsection{The fragment number}

Unit failure model is used to describe the rupture process of warhead shell in this paper. In LS-DYNA, the program cannot automatically statistical fragment number, and unit would be removed gradually with the calculation, which would lead to the fragment number lesser than the actual situation. So the distribution of fragment number and mass mainly use theoretical analysis ${ }^{[8]}$. Figure 4 is the shell rupture simulation, in which the shell material is 58SiMn and charge is RL-F.

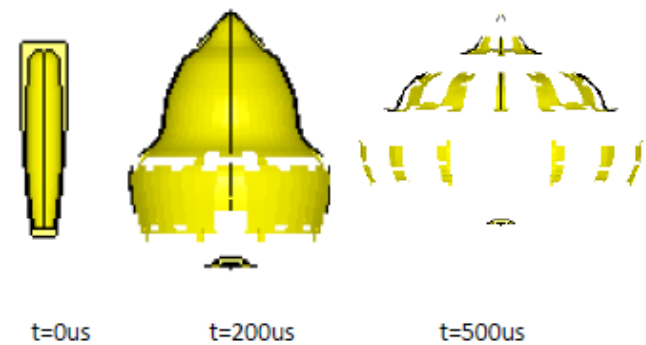

Figure 4. Shell rupture simulation

The empirical formula of shell rupture theory based on the Mott is show in Formula (1) ${ }^{[9]}$.

$N=7130\left(\frac{m}{M_{0}}\right)^{0.72}$

Where $\mathrm{N}$ refers to fragment numbers; $\mathrm{M} 0$ refers to shell metal quality; $m$ refers to charge quality.

According to the calculation of Table 1, the total fragment number is about 2100 .

\section{THE VERIFICATION TEST}

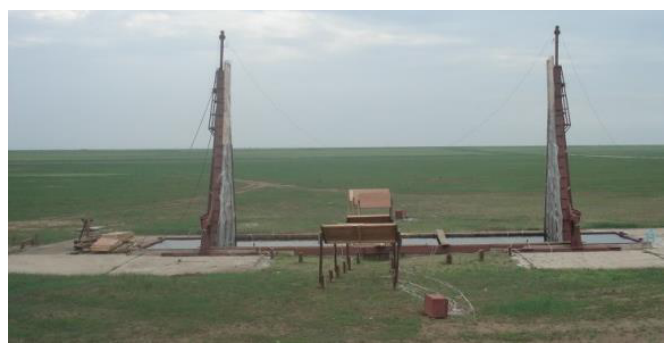

Figure 5. The comprehensive power of killing field

Figure 5 is the photograph of the power contrast test on the comprehensive power of killing field, and Table 3 is the test results. Results show that, killing power increases $25 \%$ when changing charge type and keeping shell material simultaneously, and lethal power increases $45 \%$ when changing the shell material and charge.

Table.3: The results of the power contrast test

\begin{tabular}{cccccc}
\hline shell material & charge & $\begin{array}{c}\text { fragment veloci- } \\
\text { ty }(\mathrm{m} / \mathrm{s})\end{array}$ & $\begin{array}{c}\text { fragment numbers } \\
\text { (ind) }\end{array}$ & $\begin{array}{c}\text { average lethal } \\
\text { area }\left(\mathrm{m}^{2}\right)\end{array}$ & $\begin{array}{c}\text { increase ampli- } \\
\text { tude }(\%)\end{array}$ \\
\hline 58SiMn & RL-F & 1680.10 & 2048 & 1769.20 & 25 \\
50SiMnVB & RL-F & 1607.12 & 2257 & 2061.28 & 45 \\
40Cr & RL-F & 1635.04 & 1496 & 1614.04 & 14 \\
58SiMn & TNT & 1308.98 & 2196 & 1418.88 & 0 \\
\hline
\end{tabular}




\section{CONCLUSIONS}

(1) Using the reasonable modeling method, the material model and the calculation method is accurate. The numerical results are coinciding with the test results, and accurately reflect lethality size trend of different charge warheads about different casings.

(2) When shell material is the same, RL-F high explosive charge can effectively increase the initial velocity and improve lethal power.

(3) When charge is the same, suitable shell material can effectively increase the fragment numbers and improve lethal power.

(4) For this type of the shrapnel, RL-F high explosive can make the lethal power increase by $25 \%$, and $50 \mathrm{SiMnVB}$ material of shell can make the lethal power increase by $45 \%$.

(5) Selecting high explosive and suitable shell material would reduce the charge quality, raise warhead range and keep lethal power.

\section{REFERENCES}

[1] Zhao Handong, Jin Li, Zhai Yulan, et al. 2007. Analysis on the influencing factors of the lethality about premade fragments. Journal of Projectiles, Rockets, Missiles and Guidance, 27(2): 150-151.

[2] Ma Yongzhong, Li Qixiang, et al. 2005. A calculation on casualty area of HE and analysis on influential factors. Journal of Projectiles, Rockets, Missiles and Guidance, 25(2): 346-348.

[3] Wang Lin, Gong Xiaoze, Li Zhong. 2012. The study on the effect of typical fragment mass on projectile power and the control methods. Journal of Projectiles, Rockets, Missiles and Guidance, 32(3).

[4] Ambrosini D, Luccioni B. 2006. Craters produced by explosions on the soil surface. Journal of Application Mechanics, 36: 890-900.

[5] Ambrosini D, Luccioni B, et al. 2004. Influence of soil proper-ties on craters produced by explosions on the soil surface. Mecanica Computacional, pp: 571-590.

[6] Wang J. 2001. Simulation of landmine explosion using LS-DYNA3D Software: Benchmark Work of simulation of explosion in soil and air. DSTO-TR-1168. [s.1.]: Weapons Systems Division, Aeronautical and Maritime Research laboratory.

[7] Fiserova D. 2006. Numerical Analysis of Buried Mine Explosions with Emphasis on Effect of Soil Properties on Loading. Cranfield: Cranfield University.

[8] Yang Xiumin, 2010. Numerical Simulation for Explosion and Phenomena. Hefei: University of Science and Technology of China press.

[9] Sui Shuyuan, Wang Shushan, et al. 2009. Terminal Effects. Beijing: National Defense Industry Press. 